\title{
Bucco-Adhesive Film as a Pediatric Proper Dosage Form for Systemic Delivery of Propranolol Hydrochloride: In-vitro and in-vivo Evaluation
}

This article was published in the following Dove Press journal: Drug Design, Development and Therapy

\author{
Soad A Mohamad' \\ Hesham Salem (iD ${ }^{2}$ \\ Heba A Yassin ${ }^{3}$ \\ Heba F Mansour iD ${ }^{4}$ \\ 'Department of Pharmaceutics, Faculty of \\ Pharmacy, Deraya University, Minia, \\ Egypt; ${ }^{2}$ Department of Pharmaceutical \\ Chemistry, Faculty of Pharmacy, Deraya \\ University, Minia, Egypt; ${ }^{3}$ Department of \\ Pharmaceutics, Faculty of Pharmacy, \\ Egyptian Russian University, Badr City, \\ Cairo, Egypt; ${ }^{4}$ Department of \\ Pharmaceutics, Faculty of Pharmacy, \\ Minia University, Minia, Egypt
}

Objective: To formulate and assess bucco-adhesive films of propranolol hydrochloride for pediatric use.

Methods: Different films were formulated adopting mucin, polyvinyl alcohol, chitosan and carbopol. A drug/polymer compatibility study was conducted adopting differential scanning calorimetry and Fourier transform infrared spectroscopy. The prepared films were physically investigated for variation of weight, propranolol content, thickness, surface $\mathrm{pH}$, proportion of moisture, folding endurance and mucoadhesion. In vitro drug release study and kinetic analysis of the corresponding data have been conducted. The optimized formulation was selected for a bioavailability study using albino rabbits and adopting a developed HPLC method. The pharmacokinetic parameters of the drug were calculated following administration of the optimized film and the corresponding marketed oral tablets to albino rabbits.

Key Finding: The compatibility study revealed the absence of drug/polymer interaction. The film formulations had suitable mucoadhesive and mechanical properties. The optimized formulation exhibited reasonable drug release that followed Higuchi diffusion pattern. The calculated AUC0-8h presented an enhancement in the bioavailability of propranolol hydrochloride from the selected film formulation by 1.9 times relative to the marketed propranolol oral tablets.

Conclusion: These findings support that propranolol hydrochloride bucco-adhesive film can be considered as a proper effective dosage form for pediatric delivery.

Keywords: propranolol, buccoadhesive, mucin, film, pediatric, HPLC

\section{Introduction}

Propranolol hydrochloride is a nonselective $\beta$-blocker that is commonly used in pediatrics for the treatment of cardiovascular disorders such as outflow obstructions cardiac arrhythmias, infantile hemangioma, hypertension and hypertrophic cardiomyopathy. It is accessible in the market in various oral dosage forms including tablets, sustained-release capsules and liquid solutions. Following oral administration, the drug undergoes expansive hepatic first-pass metabolism resulting in lowering its bioavailability to the range between $15 \%$ and $23 \%$. ${ }^{1}$ Furthermore, solid dosage forms as tablets and capsules are not suitable for infants and children in addition to the unacceptable taste of some solution dosage forms. Additionally, due to the short half life of propranolol hydrochloride, the drug is administered two or three times daily ${ }^{2}$ that may affect the patient compliance. As the development of appropriate formulations for kids is a major challenge, various studies have focused
Correspondence: Heba F Mansour Department of Pharmaceutics, Faculty of Pharmacy, Minia University, Minia 6IIII, Egypt

Email heba_mansour@mu.edu.eg 
on developing new dosage forms for propranolol hydrochloride including buccal formulations in an attempt to overcome these problems. ${ }^{1-4}$

The buccal route has been regularly adopted for the systemic delivery of drugs experiencing hepatic first-pass metabolism $^{5}$ or to extend drug release. ${ }^{6}$ This route has arisen as an attractive site for pediatrics systemic drug administration. ${ }^{4}$ It displays rapid onset of action, quick elimination after detaching the dosage form, easiness of self-administration and substantial enhancement in patient compliance. ${ }^{7,8}$ Buccal films as suitable formulations for young children, are thin, malleable, easily applied. These formulations guarantee accurate dosing and withstand damage caused from mouth movements. ${ }^{9-12}$ For successful retention of medication on the buccal mucosa, the buccal drug delivery system should present a mucoadhesive property. Ideal mucoadhesive properties and proper drug release depend on the polymer blend selected for film formulation. ${ }^{13}$ A combination of more than one polymer often exhibits superior properties compared to those of the individual polymers. ${ }^{14}$ Mucoadhesive systems should have adequate swelling and wetting abilities and functional groups for hydrogen-bonding. ${ }^{13}$ Mucins; a highly glycosylated protein can be considered as an outstanding adhesive element in mucoadhesive formulations. Mucin is a biocompatible polymer as it is a component of oral mucosa that is entirely protected with a mucus layer which is mainly constituted of mucins. ${ }^{13}$ It is a natural polymer with mucoadhesive properties. ${ }^{15-17}$ Mucins form gels by hydrogen bonding and entanglement depending on its concentration. ${ }^{18}$ Nevertheless, the mechanical properties of the formulation can be improved with additional hydrogel-forming component. ${ }^{19}$

The current work aimed to formulate a buccal mucoadhesive film of propranolol hydrochloride using mucin and supplementary film components such as chitosan, carbopol or polyvinyl alcohol (PVA). Glycerin and PEG 400 were adopted as plasticizers. Fourier transform infrared spectroscopy (FT-IR) and differential scanning calorimetry (DSC) were used for investigation of drug/polymer compatibility. Mucoadhesive properties and in-vitro release profiles of the produced films were investigated. Furthermore, the pharmacokinetic parameters of propranolol hydrochloride post buccal administration of the selected film formulation were compared to those obtained after oral administration of the marketed propranolol oral tablets adopting Albino New Zealand rabbits.

\section{Materials and Methods \\ Material}

Chitosan (MW 100,000-300,000), propranolol hydrochloride, agar powder, porcine stomach mucin, acetonitrile, methanol and orthophosphoric acid (HPLC grade) were purchased from Sigma-Aldrich (Germany). Potassium dihydrogen phosphate, sodium hydroxide, potassium thiocyanate, potassium chloride and calcium chloride were purchased from May \& Baker (Dagenham, England). Poly vinyl alcohol (25\% polymerization degree 5.00-2000), Carbopol 971P (CP971P), PEG 400, propylene glycol, were purchased from Fisher Chemical (Leicestershire UK). Metoprolol (99.87\%); The internal standard was supplied by Sedico Company, Egypt.

\section{Methods}

Investigation of Drug/Polymers Compatibility

Fourier Transform Infrared Spectroscopy

FTIR spectra of the unprocessed propranolol hydrochloride, PVA, chitosan, carbopol, mucin and their 1:1 physical mixture with the drug were investigated using FTIR spectrometer (Perkin Elmer, NY, USA). Samples weighing 5 $\mathrm{mg}$ were compacted into discs of potassium bromide. The spectra were attained at the wavelength range from 500 to $4000 \mathrm{~cm}^{-1}$.

\section{Differential Scanning Calorimetry}

DSC investigation of the unprocessed propranolol hydrochloride, PVA, chitosan, carbopol, mucin and their 1:1 physical mixture with the drug were carried out using a DSC-50 (Shimadzu, Kyoto, Japan). Samples were weighed in crucible pans (2-3 mg). The pans were closed with pierced caps. The temperature was elevated from 0 to $300^{\circ} \mathrm{C}$ at a rate of $5^{\circ} \mathrm{C} / \mathrm{min}{ }^{\circ} \mathrm{C}$ under a flow of nitrogen at a rate of $40 \mathrm{~mL} / \mathrm{min}$.

\section{Formulation of Propranolol Hydrochloride Bucco- Adhesive Films}

Using the solvent casting technique, different propranolol hydrochloride films were formulated. Different concentrations of mucin, PVA, chitosan and carbopol dispersions or solutions were prepared and mixed resulting in different combinations for the film formulations (Table 1). Mucin, PVA, carbopol and chitosan are film forming polymers with mucoadhesive properties imparted by mucin, carbopol, and chitosan. These combinations were physically characterized before (F1F6) and after (F7F12) drug loading. Mucin dispersion were prepared 
Table I Composition of the Prepared polymer dispersions of the Mucoadhesive Films

\begin{tabular}{|c|c|c|c|c|c|c|c|}
\hline Formulation codes & $\begin{array}{l}\text { Drug } \\
\text { (w/w\%) }\end{array}$ & $\begin{array}{l}\text { Mucin } \\
(w / w \\
\%)\end{array}$ & $\begin{array}{l}\text { PVA } \\
\text { (w/w } \\
\%)\end{array}$ & $\begin{array}{l}\text { Carbopol } 97 \text { IP } \\
\text { (w/w\%) }\end{array}$ & $\begin{array}{l}\text { Chitosan } \\
\text { (w/w\%) }\end{array}$ & $\begin{array}{l}\text { PG } \\
(w / w \\
\%)\end{array}$ & $\begin{array}{l}\text { Glycerol (w/w } \\
\%)\end{array}$ \\
\hline $\mathrm{FI}$ & - & 20 & 60 & 20 & - & - & - \\
\hline F2 & - & 40 & 40 & 20 & - & - & - \\
\hline F3 & - & 40 & 20 & 40 & - & - & - \\
\hline F4 & - & 20 & 60 & - & 20 & - & - \\
\hline F5 & _ & 40 & 40 & _ & 20 & _ & - \\
\hline F6 & - & 20 & 40 & - & 40 & - & - \\
\hline F7 & 24 & 15 & 45 & 15 & - & 0.5 & 0.5 \\
\hline F8 & 24 & 15 & 45 & - & 15 & 0.5 & 0.5 \\
\hline F9 & 24 & 15 & 45 & 15 & - & I & - \\
\hline FIO & 24 & 15 & 45 & - & 15 & I & - \\
\hline FII & 24 & 15 & 45 & 15 & - & - & 1 \\
\hline $\mathrm{FI} 2$ & 24 & 15 & 45 & - & 15 & - & I \\
\hline
\end{tabular}

by the addition of a specific amount of mucin to deionized water $(1 \mathrm{mg} / \mathrm{mL})$ and stirring for 24 hours. Then, $3 \% \mathrm{w} / \mathrm{w}$ chitosan solution was prepared by dissolving a definite amount of chitosan in acetic acid solution (1\%). PVA solution (30\% w/ w) was prepared by dissolving a specified amount of PVA in a suitable volume of distilled water under constant stirring and heating at $80^{\circ} \mathrm{C}$ till complete dissolution. Carbopol polymeric dispersion was prepared by addition of a suitable amount of carbopol $(2 \% \mathrm{w} / \mathrm{w})$ to distilled water under constant stirring. Different film formulations were obtained by various combinations of these solutions according to Table 1. Glycerine or propylene glycol as plasticizers, were included in some formulations $^{20}(0.5$ to $1.5 \% \mathrm{w} / \mathrm{w})$. Propranolol hydrochloride concentration in the prepared dispersions was $24 \% \mathrm{w} / \mathrm{w}$. The resultant dispersions were poured into suitable moulds, $1 / 2 \mathrm{~mL}$ each yielding films containing $40 \mathrm{mg}$ drug. The films were left to cast out in a well-aerated space for 24-48 hours at room temperature. ${ }^{13}$ The formed films were detached, wrapped in aluminium foil and kept in well closed containers for investigations.

\section{Characterization of Propranolol Hydrochloride Bucco- Adhesive Films}

Weight Variation, Thickness, Content Uniformity and Surface $\mathrm{pH}$. The average weight of 10 films was calculated. $^{21}$ The average thickness of three films was established by a micrometre screw gauge at five different sites. $^{22}$ The $\mathrm{pH}$ of the film surfaces was determined adopting $\mathrm{pH}$ indicator strips. ${ }^{23}$ The investigated film was left for 2 hours to swell on the surface of an agar plate. The surface $\mathrm{pH}$ was determined by using a $\mathrm{pH}$ strip positioned on the surface of the swollen film. The average content was investigated by dissolving five films separately in 100 $\mathrm{mL}$ phosphate buffer solution $(\mathrm{pH} \mathrm{6.8)}$ and spectrophotometric assay of the filtered solution at $290 \mathrm{~nm}^{24}$

\% Moisture Content. The freshly prepared formulations were weighed accurately and heated to $100-120^{\circ} \mathrm{C}$ till steady weights were obtained. The dried films were reweighed. Percentage moisture content was estimated through the following equation:

$$
\% \text { Moisture content }=\frac{\text { initial weigt-final weight }}{\text { initial weight }} \times 100
$$

Folding Endurance (Flexibility). Three films were chosen. Each film was folded repetitively at the same position till cracking occurred. The value of the folding endurance was represented by the number of film folds before cracking. ${ }^{23-25}$ The mean folding endurance $\pm \mathrm{SD}$ was considered.

\% Swelling. Three film formulations (F7F12) were weighed separately (W1) and located individually in plates of $2 \%$ agar gel. The plates were incubated for 3 minutes at $37^{\circ} \mathrm{C} \pm 1^{\circ} \mathrm{C}$. The films were detached at constant time intervals and excess water on the surface was eradicated carefully. $^{24}$ The detached films were re-weighed (W2). The swelling index (SI) was estimated adopting the following equation:

$$
\mathrm{S} 1=\frac{w 2-w 1}{w 1} \times 100
$$

Ex-Vivo Mucoadhesion Investigation. The modified Jolly balance technique ${ }^{24}$ was adopted to investigate the mucoadhesion properties of the films by determining the required force for their detachment away from a mucin gel layer. As 
mucin is the main glycoprotein in the mucous membrane, $30 \% \mathrm{w} / \mathrm{w}$ mucin gel was prepared by dispersing the specified amount of mucin powder in phosphate buffer solution $\mathrm{pH} 7.4$ by stirring for 30 minutes. By the aid of cyanoacrylate adhesive, the investigated film was fixed to a support, then hanged from a spring, and dropped to just touch the mucin layer surface (Figure 1). The film side opposite to the mucin gel was wetted with distilled water. A 20-g strength was applied to the film for 30 seconds to yield adhesion. The platform was elevated at $0.74 \mathrm{~cm} / \mathrm{s}$ until the film was detached from the mucin gel. The weight $(\mathrm{g})$ required to isolate the film from the surface of mucin display the value of the mucoadhesion strength. The mucoadhesion force was estimated using the following equation:

Mucoadhesion force $(\mathrm{N})=\frac{\text { mucoadhesive strength }}{1000} \times 9.81$

In vitro Drug Release Study. The membrane diffusion method was adopted. ${ }^{24}$ Open Nessler tubes having $3 \mathrm{~cm}$ diameter were used. A typical semi-permeable membrane was stretched with the aid of elastic bands over one end of the tubes. The film was loaded in $5 \mathrm{~mL}$ phosphate buffer solution ( $\mathrm{pH}$ 6.8) in the tube that was submersed in a beaker holding $100 \mathrm{~mL}$ of the buffer solution. This entire unit was shacked at $50 \mathrm{rpm}$ in a water-bath kept at $37 \pm$ $0.1^{\circ} \mathrm{C} .^{26,27}$ The $2 \mathrm{~mL}$ samples were removed at appropriate times and replaced with fresh phosphate buffer solution. The samples were assayed spectrophotometrically at 290 $\mathrm{nm}^{28}$ using a UV-VIS spectrophotometer (Spectronic, Genesys 2PC, NJ, USA) to determine the amount of drug released. Similarly, factor $\mathrm{f} 2$ was used for statistical analysis of the release data as the obtained release profiles were compared to a reference. ${ }^{29}$

To determine the mechanism of propranolol hydrochloride release from the selected mucoadhesive films (F7, F9, F11), data was fitted into the following kinetic models:

Zero order: $R=0^{30}$

First order: $\mathrm{R}=1-e^{-k 1} 1-e^{-k 1} t^{31}$

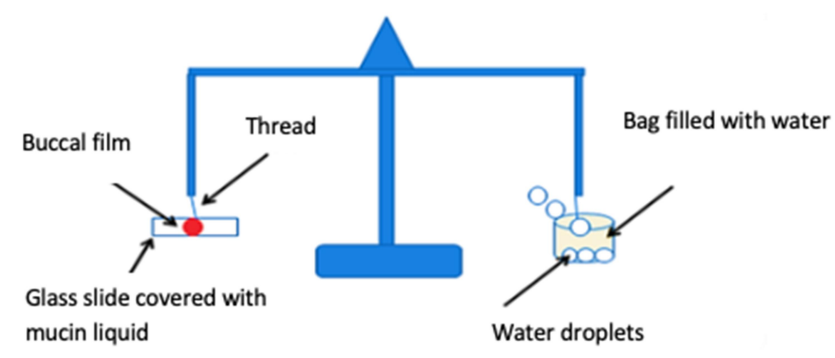

Figure I Modified Jolly balance for measuring the mucoadhesive force. ${ }^{24}$
Higuchi diffusion model: $Q=K H \times t^{1 / 232}$

Hixson-Crowell cube root law: $U R^{1 / 3}=k_{4} t^{33}$

Peppas model: $M t / M \infty=K t n^{34}$

Where $\mathrm{R}, \mathrm{Q}$ or $\mathrm{Mt} / \mathrm{M} \infty$ is the fraction of drug released at time $\mathrm{t}, \mathrm{k}$ or $\mathrm{KH}$ is the rate constant. UR is the unreleased drug fraction and $n$ is the diffusional exponent that characterizes the type of release mechanism.

Surface Morphology. Scanning electron microscope (Perkin Elmer, UK) was used to inspect the surface morphology of F11 as it had superior mechanical, mucoadhesive and release characteristics. A piece of the film was covered with a thin sheet of gold ( $150 \AA$ ) for 2 minutes under flow of argon at an atmospheric pressure of 0.3 . The covered film was imaged, and a photomicrograph was captured.

Bioavailability Study of Propranolol Hydrochloride from the Selected Mucoadhesive Film

As F11 had superior mechanical and mucoadhesive properties as well as good in-vitro release pattern, it was selected for this study. The study was accepted by the Committee of Animal Ethics of Assiut University in Assiut, Egypt. This committee confirmed that care and usage of animals followed the guides of National Institutes of Health for the care and use of Laboratory animals (NIH Publications No. 8023, revised 1978). Nine male Albino New Zealand rabbits weighing 1.5-2 kg were used. The rabbits were split into three groups of three rabbits each. The first group administered the mucoadhesive buccal film (F11) corresponding to $2.8 \mathrm{mg}$ propranolol hydrochloride. Adopting Paget and Barners table, the dose of propranolol hydrochloride for rabbit weighing 1.5 $2.5 \mathrm{~kg}=$ maximum daily human dose $(40 \mathrm{mg}) \times 0.07=2.8$ mg propranolol hydrochloride. ${ }^{35}$ The second group was given the marketed propranolol tablets; Inderal ${ }^{\circledR}$ in a comparable dose (tablet dissolved in a specific amount of water and the volume of the resultant solution equivalent to the dose was administered). The third group acted as control group. The rabbits had intraperitoneal injection of $200 \mathrm{mg} / \mathrm{mL}$ phenobarbital sodium (anaesthetic). After 10 minutes, the mucoadhesive film was applied on the buccal cavity of the rabbits after wetting with $10-\mathrm{mM}$ phosphate buffer, $\mathrm{pH}$ 6.8. On the other hand, the tablets were given to the rabbits by the aid of water. At definite time intervals of the dosage administration, blood samples $(1.5 \mathrm{~mL})$ were withdrawn from the ear vein into prelabelled heparinbeaded tubes. These samples were centrifuged for 15 minutes at $4^{\circ} \mathrm{C}$ at a speed rate of $4000 \mathrm{rpm}$ to isolate plasma that was maintained at $-80^{\circ} \mathrm{C}$ till after the analysis. 
Chromatographic Analysis of Propranolol Hydrochloride by HPLC

A perceptive selective method of high-performance liquid chromatography was established and validated for determination of propranolol $\mathrm{HCl}$ concentration in plasma samples.

\section{Preparation of Standard Solutions}

Stock standard solution of propranolol $\mathrm{HCl}\left(0.1 \mathrm{mg} \mathrm{mL}^{-1}\right)$ was prepared, daily in methanol. Working standard solutions of propranolol $\mathrm{HCl}\left(10.0 \mu \mathrm{g} \mathrm{mL}^{-1}\right)$ were prepared by appropriate dilution of the stock solutions. Aliquots of the propranolol $\mathrm{HCl}$ working solutions were separately diluted with methanol in $10-\mathrm{mL}$ volumetric flasks to get serial concentrations ranging from 0.2 to $3.0 \mu \mathrm{g} \mathrm{mL}^{-1}$. The concentration of the internal standard solution was $5 \mu \mathrm{g} \mathrm{mL}^{-1}$.

\section{Sample Preparations}

Firstly, $0.7 \mathrm{~mL}$ of the frozen blank plasma was defrosted at room temperature. Then the plasma was spiked with a definite volume of the previously diluted solutions of propranolol $\mathrm{HCl}(100 \mu \mathrm{L})$ to get concentrations ranging from 0.2 to $3.0 \mu \mathrm{g} \mathrm{mL}^{-1}$. Finally, a volume of $100 \mu \mathrm{L}$ of the I.S was added to have a concentration of $5 \mu \mathrm{g} \mathrm{mL}^{-1}$.

\section{Analysis Conditions and Method Validation}

- A chromatographic system; La chrom, Merck Hitachi series (Kinesis, UK) having a pump L-7110 and wavelength UV-VIS detector L-7420 as well as Column X terra ${ }^{\circledR}$ RP-C18column; $150 \mathrm{~mm} \times 4.6 \mathrm{~mm}$, $5 \mu \mathrm{m}$ particle size (Waters Corporation) were employed. The mobile phase was a mixture of acetonitrile and $0.05 \mathrm{M}$ potassium dihydrogen orthophosphate (40: $60, \mathrm{v} / \mathrm{v})$ of $\mathrm{pH} 3.6$ that was adjusted using orthophosphoric acid. The analysis was carried out at room temperature and flow rate of $1 \mathrm{~mL} \mathrm{~min}^{-1}$ under isocratic conditions and using UV detector at 220 nm. This method was validated regarding linearity, sensitivity, accuracy, precision, specificity, and stability according to "The Guidance for Industry Bioanalytical Method Validation" published by the Food and Drug Administration. ${ }^{36}$

\section{Pharmacokinetic Analysis}

Pharmacokinetic parameters including first propranolol detection in the plasma (Tlag), maximum concentration of drug in plasma (Cmax) and corresponding time
(Tmax) were determined from the plasma concentrationtime profile of each animal. The extent of drug absorption was estimated by measuring the areas under the plasma concentration-time curve (Trapezoidal method) from the zero time till the final blood sampling point ( 8 hours post administration). The parameters from each animal were represented as individual values. One-way analysis of variance with $95 \%$ confidence interval was used to assess the statistical significance of differences between the essential pharmacokinetic parameters of propranolol hydrochloride buccal mucoadhesive films and the corresponding marketed oral tablets of propranolol.

\section{Results}

FTIR spectra of propranolol hydrochloride and its physical mixtures with chitosan, PVA, carbopol and mucin are shown in Figure 2. The drug showed a characteristic absorption peak of NH group at $3467 \mathrm{~cm}^{-1} 37$ Chitosan exhibited a wide band at $3,448 \mathrm{~cm}^{-1}$ and an absorption peak at $2,800 \mathrm{~cm}^{-1}$ analogous to the symmetrical vibration of N-H and the stretch vibrations of $\mathrm{C}-\mathrm{H}$, respectively. Chitosan spectrum also showed amide absorption peaks at 1,658 and $1,322 \mathrm{~cm}^{-1}$, respectively. Additionally, the spectrum displayed peaks at 1,382 $\mathrm{cm}^{-1}$ and $1,423 \mathrm{~cm}^{-1}$ analogous to the $\mathrm{CH} 3$ symmetrical deformation mode; wide bands at $1,031 \mathrm{~cm}^{-1}$ and 1,081 $\mathrm{cm}^{-1}$ analogous to the stretching vibration of C-O. Other peaks were detected around $1,155 \mathrm{~cm}^{-1}$ and $894 \mathrm{~cm}^{-1}$ analogous to saccharide. ${ }^{38}$ The PVA spectrum showed a wide band ranging from $3,550 \mathrm{~cm}^{-1}$ to $3,200 \mathrm{~cm}^{-1}$ analogous to stretching of the O-H group and another characteristic peak between $2,840 \mathrm{~cm}^{-1}$ and $3,000 \mathrm{~cm}^{-1}$ analogous to $\mathrm{C}=\mathrm{H}$ stretching vibration of the alkyl groups. ${ }^{39}$ Carbopol showed a characteristic peak at $1,700 \mathrm{~cm}^{-1}$ corresponding to C-O stretching vibration. ${ }^{40}$ The FTIR spectrum of the physical mixture of propranolol hydrochloride with chitosan, PVA, carbopol or mucin revealed the presence of the characteristic peaks of the individual components.

Figure 3 shows DSC thermograms of propranolol hydrochloride and its physical mixtures with chitosan, PVA, carbopol or mucin. Propranolol hydrochloride showed an endothermic peak at $164^{\circ} \mathrm{C}$ corresponding to its melting point. ${ }^{41}$ The DSC thermograms of chitosan, carbopol and mucin showed a broad peak from $80^{\circ} \mathrm{C}$ to $100^{\circ} \mathrm{C}$ reflecting the classic thermal performance of surface water loss. ${ }^{24}$ However, the physical mixtures showed the characteristic melting endotherm of the drug. 


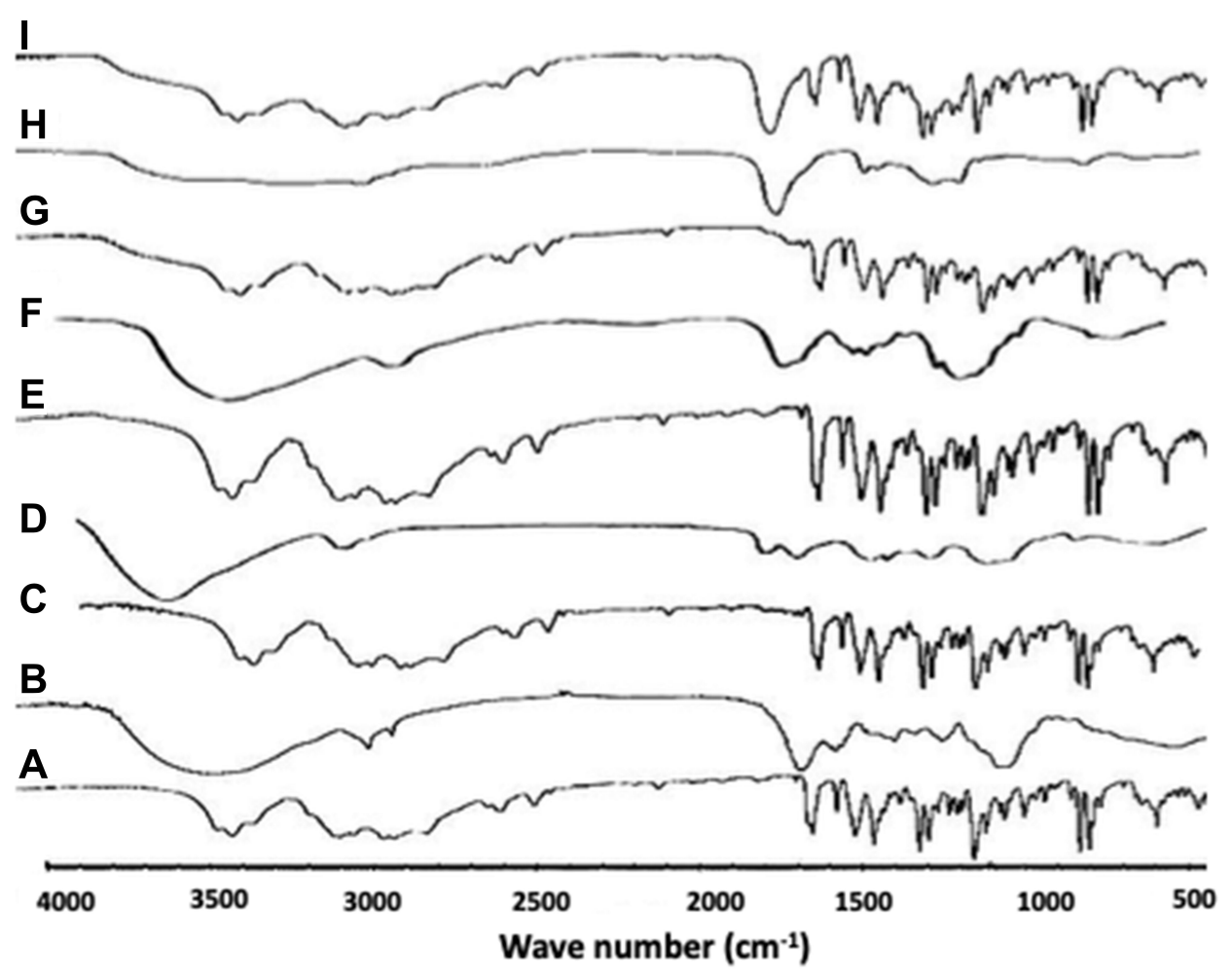

Figure 2 FTIR of (A) propranolol hydrochloride, (B) mucin, (C) propranolol/mucin physical mixture, (D) PVA, (E) propranolol/PVA physical mixture, (F) chitosan, (G) propranolol/chitosan physical mixture, (H) carbapol, and (I) propranolol/carbapol physical mixture.

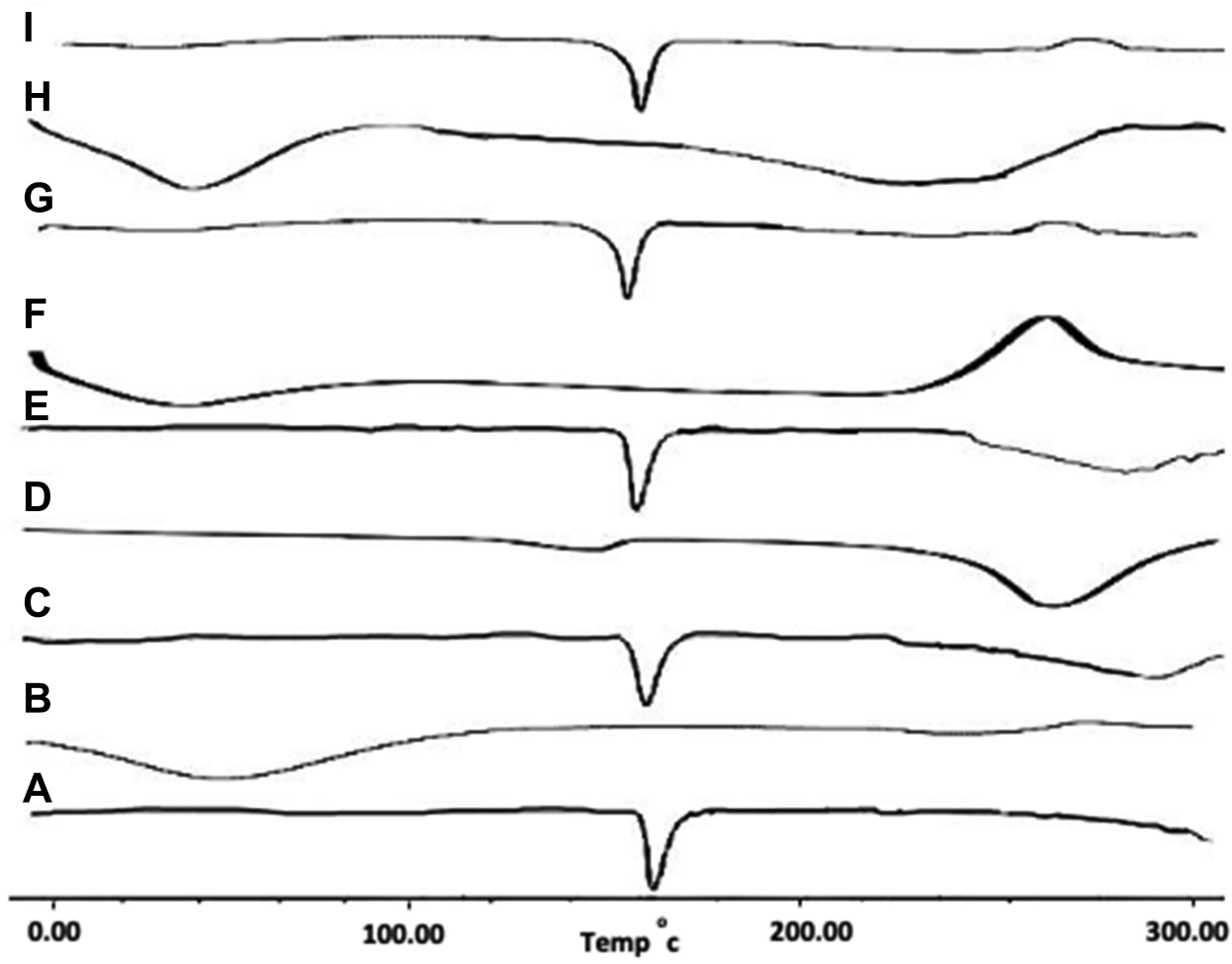

Figure 3 DSC of (A) propranolol hydrochloride, (B) mucin, (C) propranolol/mucin physical mixture, (D) PVA, (E) propranolol/PVA physical mixture, (F) chitosan, (G) propranolol/chitosan physical mixture, (H) carbapol, and (I) propranolol/carbapol physical mixture. 


\section{Characterization of Propranolol Hydrochloride Bucco-Adhesive Films}

Table 2 shows the physical properties of the prepared film formulations. It reveals that the average weight of all formulated films ranged from $0.07 \pm 0.1$ to $0.3 \pm 0.1 \mathrm{~g}$. The drug contents of the medicated films ranged from 96 $\pm 0.3 \%$ to $98.7 \pm 0.1 \%$ revealing content uniformity. The thickness of films ranged from $0.12 \pm 0.0$ to $0.21 \pm 0.1 \mathrm{~mm}$. The majority of the films displayed a $\mathrm{pH}$ ranging from 5.3 \pm 0.1 to $6.5 \pm 0.1$. The swelling behaviors of F7F12 are shown in Figure 4. These formulations demonstrated an increase in the swelling capability after 10 minutes relative to other formulations. F12 displayed the most suitable and acceptable swelling profile as erosion occurred after 10 minutes and thus, the drug release began and sustained to 50 minutes. The percentage of moisture contents of the prepared film formulations ranged from $2.5 \pm 0.1$ to $5.7 \pm$ 0.1 . It is clear that increasing the amount of carbopol (F1, F2, F3, F7, F9, F11) resulted in increasing moisture content. On the other hand, increasing the chitosan content (F4, F5, F6, F8, F10, F12) resulted in decreasing the moisture content. F12 and F6 showed the maximum and minimum folding endurance, respectively $(450 \pm 9$ and $180 \pm 3)$. F1F6 showed low folding endurance $(180 \pm 30$ to $250 \pm 23$ ) while F7F12 displayed higher values for folding endurance $(310 \pm 15$ to $450 \pm 30)$. F11 exhibited folding endurance of $330 \pm 7$.

\section{Mucoadhesion Study}

The results of the mucoadhesion study for F7F12 are presented in Figure 5. These films showed mucoadhesive forces ranging from $0.18 \pm 0.05$ to $0.21 \pm 0.03 \mathrm{~N}$. F11 and

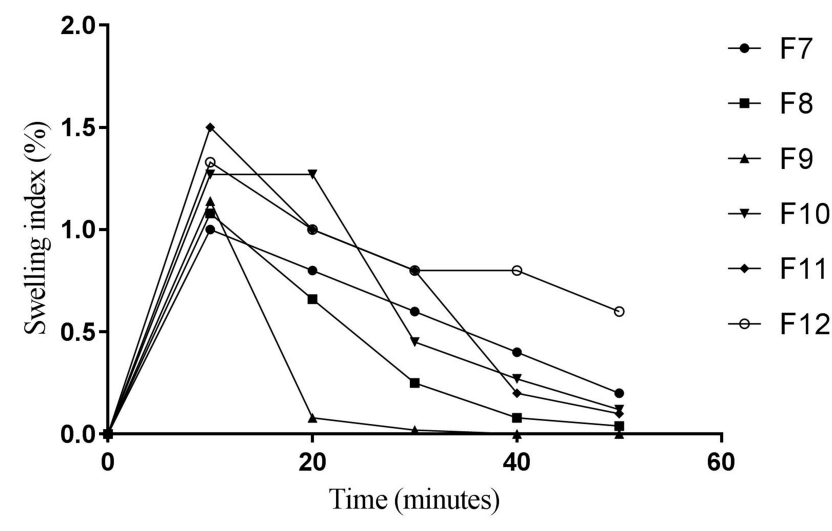

Figure 4 Swelling profile of propranolol buccal films.

F12 displayed somewhat superior mucoadhesive force compared to other formulations.

\section{In vitro Drug Release Study}

Figure 6 represents the in vitro drug release profiles of propranolol hydrochloride from the selected formulations F7-F12. Both of the chitosan-based films; F10 and F12 demonstrated $20-40 \%$ amount of drug release within the first 60 minutes while more than $70 \%$ propranolol hydrochloride released from carbopol-based formulations; F7 and F11 at the same time period displaying faster drug release relative to other formulations. The differences in the release profiles of propranolol hydrochloride from chitosan-based films (F10, F12) and carbopol-based formulations (F7, F11) were statistically significant ( $\mathrm{f} 2<50$ ). However, F8 (chitosan-based) showed a significantly higher amount of drug release $(\mathrm{f} 2<50)$ compared to the other chitosan-based films (F10, F12). On the other hand, F9 (carbopol-based) showed a significantly lower amount of drug release

Table 2 Different Physicochemical Characterization of the Prepared Films

\begin{tabular}{|l|l|l|l|l|l|}
\hline Formulation Codes & Weight $(\mathbf{m g})$ & Thickness $(\mathbf{m m})$ & Surface $\mathbf{p H}$ & Moisture Content \% & Drug Content (mg\%) \\
\hline FI & $0.1 \pm 0.1$ & $0.18 \pm 0.2$ & $5.8 \pm 0.1$ & $5 \pm 0.5$ & - \\
F2 & $0.15 \pm 0.01$ & $0.21 \pm 0.1$ & $5.3 \pm 0.1$ & $2.5 \pm 0.1$ & - \\
F3 & $0.12 \pm 0.0$ & $0.2 \pm 0.2$ & $5.8 \pm 0.1$ & $3.2 \pm 0.4$ & - \\
F4 & $0.26 \pm 0.1$ & $0.12 \pm 0.0$ & $5.1 \pm 0.0$ & $4.3 \pm 0.1$ & - \\
F5 & $0.15 \pm 0.0$ & $0.14 \pm 0.1$ & $4 \pm 0.1$ & $3 \pm 0.2$ & - \\
F6 & $0.24 \pm 0.01$ & $0.18 \pm 0.1$ & $4.5 \pm 0.1$ & $5.7 \pm 0.1$ & - \\
F7 & $0.18 \pm 0.1$ & $0.14 \pm 0.1$ & $5.2 \pm 0.0$ & $3.3 \pm 0.1$ & $98 \pm 0.2$ \\
F8 & $0.07 \pm 0.1$ & $0.18 \pm 0.1$ & $5.4 \pm 0.2$ & $5.6 \pm 0.5$ & $97.8 \pm 0.3$ \\
F9 & $0.2 \pm 0.1$ & $0.13 \pm 0.0$ & $5.6 \pm 0.1$ & $3.2 \pm 0.1$ & $99 \pm 0.1$ \\
FI0 & $0.14 \pm 0.2$ & $0.19 \pm 0.0$ & $6.2 \pm 0.0$ & $5.3 \pm 0.3$ & $98.5 \pm 0.2$ \\
FII & $0.3 \pm 0.1$ & $0.18 \pm 0.2$ & $5.9 \pm 0.1$ & $3.5 \pm 0.1$ & $96 \pm 0.3$ \\
FI2 & $0.11 \pm 0.1$ & $0.14 \pm 0.0$ & $6.5 \pm 0.1$ & $5.5 \pm 0.2$ & $98.7 \pm 0.1$ \\
\hline
\end{tabular}




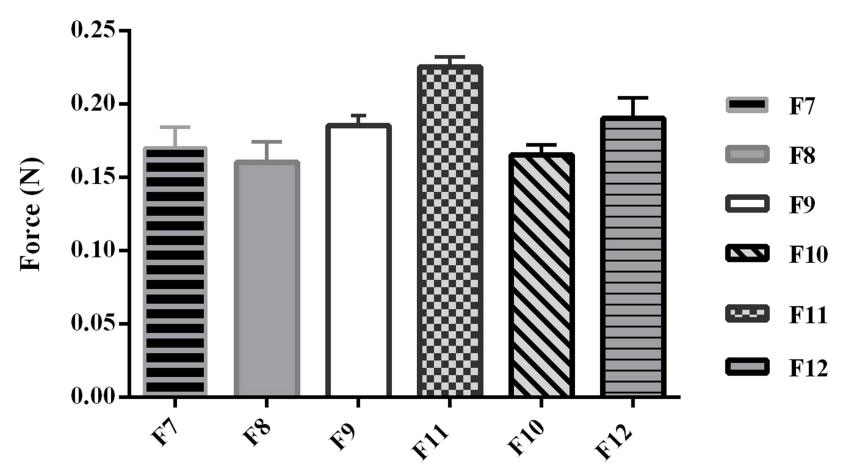

Figure 5 Mucoadhesive characteristics of propranolol buccal films.

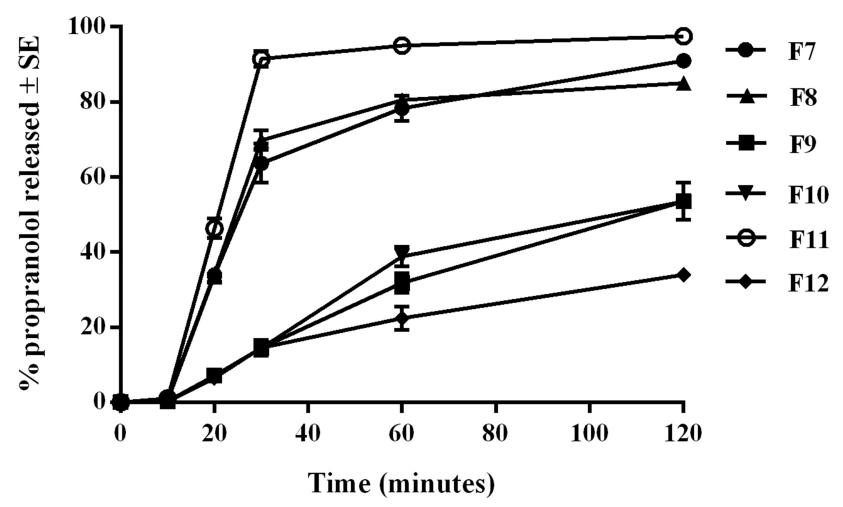

Figure 6 In vitro release profile of the selected propranolol buccal films $(n=3)$.

compared to the other carbopol-based films (F7, F11). Table 3 displays the drug release relative to different kinetics models; data were fitted to the selected models. According to the value of $\mathrm{r}^{2}$, the release of propranolol hydrochloride from all film formulations followed the Higuchi diffusion model.

\section{Surface Morphology}

Figure 7 displays the morphological features of F11 and its corresponding drug-free formulation. The drug-free film

Table 3 Release kinetics of Propranolol Hydrochloride from Different Films

\begin{tabular}{|l|l|l|l|l|l|l|l|}
\hline \multirow{2}{*}{$\begin{array}{l}\text { Formulation } \\
\text { Codes }\end{array}$} & \multicolumn{6}{|l|}{ Correlation coefficient } \\
\cline { 2 - 8 } & Zero & First & Higuchi & Hixon & \multicolumn{2}{l|}{ Baker } & \multicolumn{2}{|l|}{ Peppas } \\
\cline { 6 - 9 } & & & & & & R & $\mathbf{n}$ \\
\hline F7 & 0.78 & 0.78 & 0.90 & 0.77 & 0.78 & 0.88 & 0.5 \\
F8 & 0.78 & 0.78 & 0.95 & 0.78 & 0.78 & 0.90 & 0.7 \\
F9 & 0.78 & 0.78 & 0.94 & 0.8 & 0.78 & 0.89 & 0.6 \\
F10 & 0.78 & 0.78 & 0.98 & 0.88 & 0.78 & 0.95 & 1 \\
FII & 0.78 & 0.78 & 0.96 & 0.80 & 0.78 & 0.92 & 0.45 \\
F12 & 0.79 & 0.79 & 0.96 & 0.79 & 0.95 & 0.91 & 0.72 \\
\hline
\end{tabular}
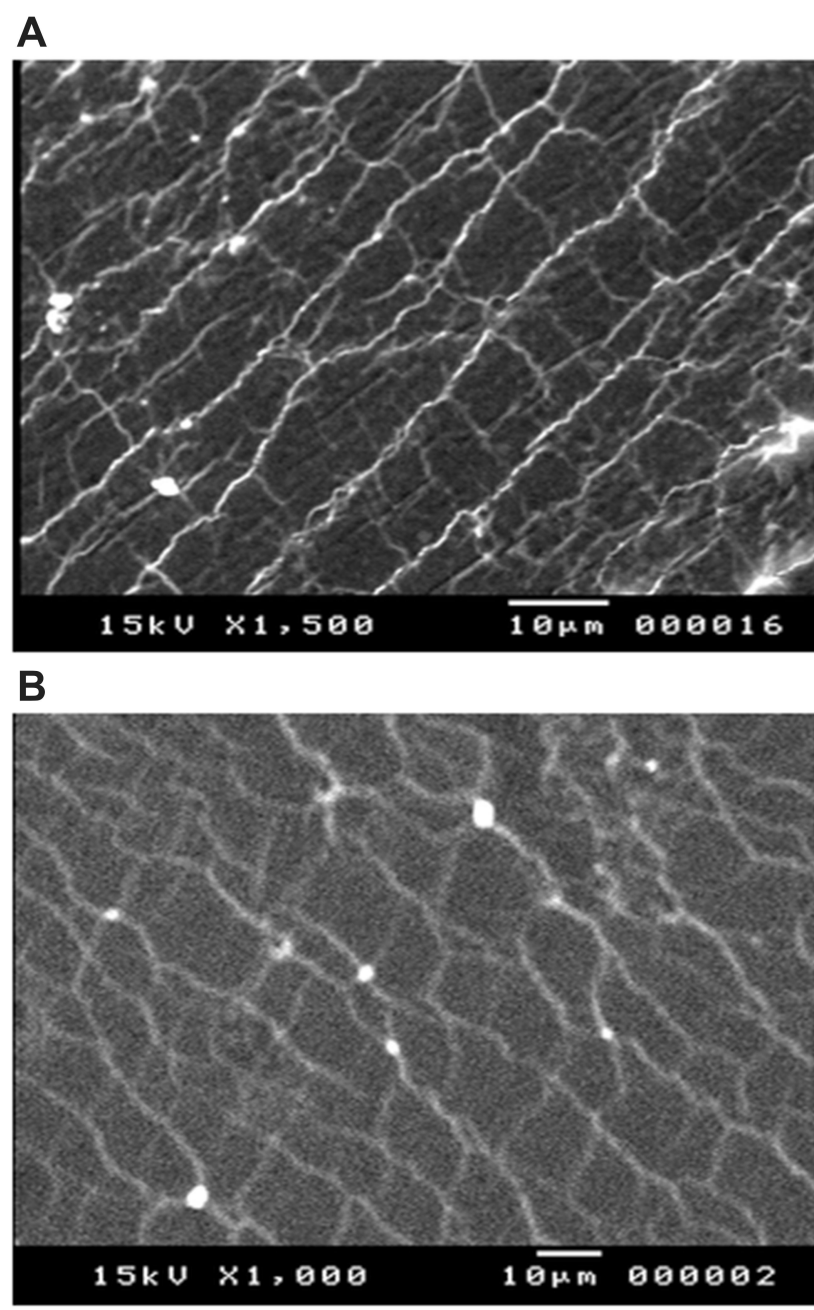

Figure 7 SEM of (A) plain film and (B) FII film formulation.

(Figure 7A) reveals extended, nearly rod-like structures with a smooth and even contour (threads with loops and kinks). F11 (Figure 7B) exhibited no evident drug particles aggregation.

\section{Validation of the Chromatographic Method of Propranolol Hydrochloride Analysis}

The calibration curve was linear in the concentration range of $0.2-3.0 \mu \mathrm{g} \mathrm{mL}^{-1}$ for the studied propranolol $\mathrm{HCl}$. The validation parameters are displayed in Table 4. Determination coefficient $\left(\mathrm{r}^{2}\right)$ of the calibration curves was $\geq 0.999$. The lowest limit of quantification (LLOQ) for propranolol $\mathrm{HCl}$ was calculated to be $0.121 \mu \mathrm{g} \mathrm{mL}$, with a signal to noise ratio $(\mathrm{S} / \mathrm{N})$ of 5.5. The intra-day and inter-day precision and accuracy of five concentrations of propranolol $\mathrm{HCl}$ were less than 2.82 and 2.94, respectively. The intra-day accuracy ranged from 87.43 to $97.48 \%$. Retention times of propranolol $\mathrm{HCl}$ and the IS 
Table 4 Validation Parameters for the Proposed HPLC Method for Determination of Propranolol Hydrochloride in Plasma

\begin{tabular}{|l|l|}
\hline Validation Parameters & $\begin{array}{l}\text { Standard Propranolol } \\
\mathbf{H C l}\end{array}$ \\
\hline Linearity range $\left(\mu \mathrm{gL}^{-1}\right)$ & $0.2-3$ \\
Slope & 127.44 \\
Intercept & -0.459 \\
Number of determinations & 15 \\
Determination coefficients & 0.999 \\
Limit of detection, LOD $\left(\mu \mathrm{gL}^{-1}\right)$ & 0.046 \\
Limit of determination, LOQ $\left(\mu \mathrm{gL}^{-1}\right)$ & 0.121 \\
\hline
\end{tabular}

were $4.714 \pm 0.10 \mathrm{~min}, 0.923 \pm 0.12 \mathrm{~min}$, respectively. At these retention times, no substantial interference from endogenous peaks was spotted. Peak areas attained from freshly prepared extracted samples and standard solutions of the same concentration were compared to calculate the absolute recovery. The data was estimated at low, medium and high concentrations in triplicates as suggested by the FDA guidelines. The mean percent recovery values of propranolol $\mathrm{HCl}$ at low, medium and high-quality control levels are shown in Table 5. The recovery of propranolol $\mathrm{HCl}$ from plasma using the acetonitrile/methanol mixture was good. The stability of propranolol $\mathrm{HCl}$ under various conditions was studied. All results meet the approval criteria of $\pm 15 \%$ deviation from the nominal concentration.

Table 5 Precision and Accuracy of the Proposed HPLC Technique for Determination of Standard Propranolol Hydrochloride

\begin{tabular}{|c|c|c|c|c|}
\hline $\begin{array}{l}* \text { Conc. Taken } \\
\mu \mathrm{g} \cdot \mathrm{mL}^{-1}\end{array}$ & $\begin{array}{l}\text { Area } \\
\text { Under } \\
\text { the Cure }\end{array}$ & $\begin{array}{l}\text { Conc. Found } \\
\mu \mathrm{g} \cdot \mathrm{mL}^{-1}\end{array}$ & $\begin{array}{l}\text { Recovery } \\
\%\end{array}$ & $\pm S D$ \\
\hline 0.2 & 25.4 & 0.202 & 101.00 & +1.00 \\
\hline 0.4 & 50.8 & 0.401 & 100.25 & +0.25 \\
\hline 0.6 & 76.3 & 0.600 & 100.00 & +0.00 \\
\hline 0.8 & 101.6 & 0.809 & 101.12 & +1.12 \\
\hline I & 127 & 1.002 & 100.20 & +0.20 \\
\hline 1.2 & 152.4 & 1.190 & 99.16 & -0.84 \\
\hline 1.4 & 177.8 & 1.398 & 99.86 & -0.14 \\
\hline 1.6 & 203.2 & 1.598 & 99.87 & -0.13 \\
\hline 1.8 & 228.6 & 1.797 & 99.83 & -0.17 \\
\hline 2 & 254 & 1.996 & 99.80 & -0.20 \\
\hline 2.2 & 279.4 & 2.195 & 99.77 & -0.23 \\
\hline 2.4 & 304.8 & 2.395 & 99.80 & -0.20 \\
\hline 2.6 & 330.2 & 2.594 & 99.76 & -0.24 \\
\hline 2.8 & 355.6 & 2.793 & 99.75 & -0.25 \\
\hline 3.0 & 384.6 & 3.021 & 100.72 & +0.72 \\
\hline Mean \pm SD & & & 100.06 & 0.38 \\
\hline
\end{tabular}

Notes: *Average of three experiments

\section{Bioavailability Study}

Plasma concentration-time profiles post administration of a single dose of the selected buccal film formulation F11 or the solution of the commercially available propranolol hydrochloride oral tablets (equivalent dose of the drug); are shown in Figure 8. The plasma concentration of propranolol post administration of the oral tablet solution began with minimum concentration of $0.54 \pm 0.12 \mu \mathrm{g} /$ $\mathrm{mL}$ at 15 minutes (Tlag) and increased to a maximum concentration (Cmax) of $2.24 \pm 0.1 \mu \mathrm{g} / \mathrm{mL}$ at 120 minutes followed by gradual drop with time. The plasma concentration of propranolol post administration of F11 began with minimum concentration of $0.12 \pm 0.09 \mu \mathrm{g} / \mathrm{mL}$ at 5 minutes (Tlag) that gradually increased to a maximum concentration of $2.35 \pm 0.22 \mu \mathrm{g} / \mathrm{mL}$ at 75 minutes and followed by a drop with time at a comparable rate to that of the oral tablets. Tmax of F11 (75 minutes) was significantly lower $(p<0.01)$ than that of the oral tablet solution (120 min). Generally, propranolol plasma concentrations after administration of the film formulation were significantly higher than those attained post administration of the solution of the oral tablets $(p<0.05)$ although having approximately the same Cmax. Tmax of F11 (75 minutes) was shorter than that of the oral tablets (120 minutes). The calculated AUC0-8h values for the oral tablet solution and F11 were $800,20 \pm 145$ and $1527.49 \pm 189 \mu \mathrm{g} / \mathrm{mL} / \mathrm{min}$, respectively. Thus, the anticipated bioavailability of the drug from F11 was significantly higher than that of the oral tablets $(p<0.05)$ by 1.9 -fold.

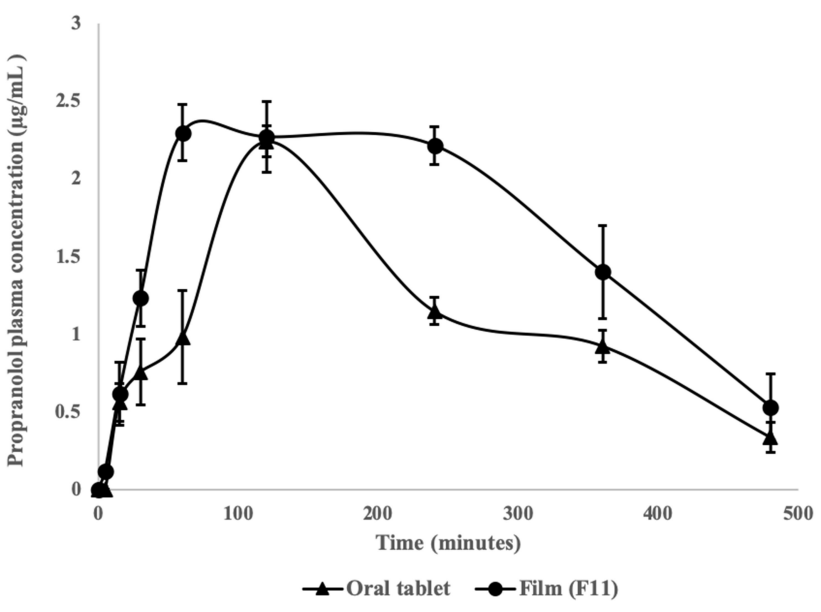

Figure 8 Mean plasma concentration-time profiles of propranolol hydrochloride after buccal administration of FII or oral Inderal ${ }^{\circledR}$ tablets to Albino New Zealand rabbits. 


\section{Discussion}

FTIR and DSC were used to evaluate the compatibility between propranolol hydrochloride and the anticipated polymers and to detect the probability of incidence of drug/polymer interaction. The presence of the characteristic peaks of the individual components in the FTIR spectra of the physical mixtures of propranolol hydrochloride with chitosan, PVA, carbopol or mucin revealed the absence of drug/polymers physicochemical interactions. The existence of the characteristic melting endotherm of the drug in the DSC thermograms of the physical mixtures indicates the absence of physical interaction between the drug and the polymers supporting the FTIR results.

The calculated weight variation was satisfactory which reveals the appropriateness of the applied preparation procedures. The thickness of different films was suitable for further studies. ${ }^{42}$ The measured $\mathrm{pH}$ of the prepared films was slightly deviated from that of the buccal mucosa omitting any irritation. ${ }^{43}$ The mucoadhesive ability of the buccal film is influenced by its swelling behavior that depends to a great extent on the structure and content of the film. By the increase in the hydration level, the mucoadhesion improves till reaching certain limit after which excess hydration results in an abrupt fall in the mucoadhesion as a result of loosening at the boundary between the polymer and the tissue. ${ }^{44}$ Additionally, film swelling accelerates the release of the drug by diffusion and erosion. The increase in the swelling capacity of F7F12 after 10 minutes compared to other formulations might be attributed to the presence of free hydroxyl groups in a great amount in glycols included in these formulations. ${ }^{45}$ The negligible difference in the percentage of moisture in the films might be due to the variation in the type and concentration of the polymer content. The ideal moisture amount in the film formulations is essential for the stability of the film, non-susceptibility for microbial growth, and non-fragility. ${ }^{25,46}$ The increase in the moisture content as a result of increasing the amount of carbopol in F1, F2, F3, F7, F9 and F11 might be due to the high percentage of carboxylic acid groups that that enhance the polymer swelling. ${ }^{47,48}$ On the other hand, the decrease in the moisture content as a result of increasing the chitosan content in F4, F5, F6, F8, F10, and F12 might be attributed to compactness of the film network. ${ }^{49,50}$

Mechanical strength and elasticity of the film was determined through measuring its folding endurance that showed its ability to adapt to the shape of the buccal cavity after administration. A firm film may induce irritation, distress, and loss of the drug due to fragmentation during or after application. ${ }^{51}$ Folding endurance supports suitable elasticity of the formulated films. Due to the absence of plasticizers in F1F6, these films displayed lower folding endurance values and thus lower elasticity compared to F7F12. That of F11 indicated good elasticity and was intimate to the reported ideal folding endurance for the buccal film. ${ }^{24,25}$ Depending on the folding endurance results, F7-F12 were selected for further investigations. Mucoadhesion is desirable for prolonging the time of contact between the film and buccal tissues and consequently specifying prolongation of the drug release. The considerable mucoadhesive properties of the selected films might be due to the ability of the hydrophilic polymers chitosan and PVA to form different types of bonding including hydrogen bonding resulting in a robust gel. Similar results have been reported for the mucoadhesive buccal films of vitamin B12 and glibenclamide. ${ }^{24,52}$ Chitosan buccal films have been reported to have proper mucoadhesive characteristics as its protonated amino groups go through electrostatic attractions with the negatively charged mucus layer of the buccal cavity. Also, hydroxyl and amino groups of chitosan form hydrogen bonds with the mucus layer. ${ }^{53}$ Furthermore, molecules of chitosan have the ability to interpenetrate the mucin layer due to its sufficient chain elasticity. ${ }^{54}$ The superior mucoadhesive force of F11and F12 compared to other formulations might be due to the high percentage of glycerine that contains a great number of the hydrophilic hydroxyl groups, hence leading to formation of a robust gel through hydrogen bonding that infiltrates powerfully into the mucin layer.

The slow drug release from chitosan-based films; F10 and F12 might be attributed to the slow erosion rate of the high molecular weight polymer. $^{55}$ On the other hand, higher drug release from the carbopol-based; F7 and F11 might be due to water absorption by the more hydrophilic polymer carbopol. ${ }^{56}$ This property improved the wetting and swelling ability that enhanced permeation of water into the film matrix, and thus augmented drug diffusion. The higher amount of drug released from F8 (chitosanbased) compared to the other chitosan-based films (F10, F12) might be attributed to the presence of propylene glycol and glycerol in the formulation that might improve the break-up of the film and hence drug release. ${ }^{24}$ On the other hand, the lower amount of drug released from F9 (carbopol-based) compared to the other carbopol-based 
films (F7, F11) might be attributed to the exclusion of glycerol in this film formulation. The release data of propranolol hydrochloride from all films was best fit to Higuchi diffusion kinetics that was in accordance with various studies of bucco-adhesive films. ${ }^{52,57}$

Surface morphology of the plain film suggests high flexibility of the film. The existence of obvious branch points is elucidated by the formation of closed loops. The length variation of these structures and their random appearance along the chain possibly indicate that mucins have virtually infinite configurational possibilities. ${ }^{58,59}$ The absence of drug particles aggregation in the medicated film scan recommends good distribution of propranolol hydrochloride in the polymer matrix (mucin, PVA, and carbopol). Therefore, the formulated film was dense and homogenous with noticeable phase homogeneity.

The developed chromatographic method of propranolol HCL analysis was accurate and precise. Specificity was evaluated to prove that the presence of the biological matrix did not affect the quantity measurement of the anticipated analyte. The extraction method using acetonitrile/methanol mixture reliably excluded interfering subjects from plasma as indicated by the good recovery of propranolol $\mathrm{HCl}$. The shorter Tmax and the higher propranolol plasma concentrations of F11 compared to that of the oral tablet solution indicates more rapid absorption of the drug from the film than the oral tablets. Furthermore, the superior AUC0- $8 \mathrm{~h}$ values of F11 compared to that of the oral tablet suggests improved bioavailability. This drug bioavailability enhancement from the bucco-adhesive film might be due to the high vasculature, intimate adherence between the film and the surface of absorption as well as the prolonged contact time of the film at the buccal mucosa that was attained by the proper mucoadhesive properties of the film. Similar results have been obtained for dimenhydrinate as the area under the curve AUC0-7 $\mathrm{h}$ value of the corresponding mucoadhesive buccal film was two-fold higher than the drug oral solution. ${ }^{60}$ Moreover, ondansetron hydrochloride, and Zolpidem have experienced enhanced bioavailability from buccal film formulations. ${ }^{61,62}$ Therefore, the superior bioavailability of propranolol hydrochloride from the bucco-adhesive film compared with the solution of propranolol oral tablets might be related to the fact that the drug absorption from the buccal mucosa was better than that from the gastrointestinal tract. Consequently, the in vivo study confirmed that the formulated propranolol hydrochloride bucco-adhesive film; F11 can be adopted as an effective alternative for the corresponding marketed oral tablets to avoid preparation of propranolol solution from the oral tablets for adjustment of the adult dose to be suitable for pediatric use. It worth knowing that it has been reported that propranolol causes inconsiderable irritation that can be accepted. Wang et al, ${ }^{63}$ have reported that sublingual Promptol ${ }^{\mathrm{TM}}$ tablets might trigger slight local irritation. ${ }^{63}$ Comparable insignificant irritation has been also detected in other studies for sublingual propranolol. ${ }^{64,65}$ Thus, according to these studies, short-term use of buccal propranolol is thought to be reasonably safe for children.

\section{Conclusions}

The formulated propranolol hydrochloride bucco-adhesive films including mucin had a uniform phase. The compatibility study indicated the absence of interactions between the drug and the used polymers. Mucoadhesive buccal film containing $24 \% \mathrm{w} / \mathrm{w}$ propranolol hydrochloride, $15 \% \mathrm{w} / \mathrm{w}$ mucin, and 45\% w/w PVA and 15\% carbopol and 1\% glycerol (F11) displayed acceptable mucoadhesive and mechanical properties. F11 displayed great mucoadhesion force and a proper in vitro drug release profile. The in vivo study revealed that propranolol hydrochloride bioavailability from the bucco-adhesive film (F11) was 1.9 times that from the analogous solution of the marketed oral tablets. This finding supports that the bucco-adhesive film of propranolol hydrochloride can be a promising and convenient dosage form for pediatric use.

\section{Acknowledgment}

The authors acknowledge Mrs Madcour for her valuable contribution in helping with the animal study.

\section{Disclosure}

The authors report no conflicts of interest in this work.

\section{References}

1. Patel VM, Prajapati BG, Patel HV, Patel KM. Mucoadhesive bilayer tablets of propranolol hydrochloride. AAPS PharmSciTech. 2007;8: E203-E208. doi:10.1208/pt0803077

2. Bialy LP, Wojcik C, Mlynarczuk-Bialy I. Mucosal delivery systems of antihypertensive drugs: A practicalapproach in general practice. Biomed Pap Med Fac Univ Palacky Olomouc Czech Repub. 2018;162:71-78. doi:10.5507/bp.2018.022

3. Patel VM, Prajapati BG, Patel MM. Formulation, evaluation, and comparison of billayered and multi-layered mucoadhesive buccal devices of propranolol hydrochloride. AAPS PharmSciTech. 2007;8: E147-E154. doi:10.1208/pt0801022

4. Abruzzo A, Nicoletta FP, Dalena F, Cerchiara T, Luppi B, Bigucci F. Bilayered buccal films as child-appropriate dosage form for systemic administration of propranolol. Int J Pharm. 2017;31(1):257-265. doi:10.1016/j.ijpharm.2017.08.070 
5. Adhikari SNR, Nayak BS, Nayak AK, Mohanty B. Formulation and evaluation of buccal patches for delivery of atenolol. AAPS PharmSciTech. 2010;11(3):1038-1044. doi:10.1208/s12249-010-9459-z

6. Viral HS, Pragna S, Gaurang BS. Design and evaluation of thiolated chitosan based mucoadhesive and permeation enhancing bilayered buccal drug delivery system. African J Pharm Pharmacol. 2012;6 (7):491-501.

7. Lam JK, Xu Y, Worsley A, Wong IC. Oral transmucosal drug delivery for pediatric use. Adv Drug Deliv Rev. 2014;73:50-62. doi:10.1016/j.addr.2013.08.011

8. Patel VF, Liu F, Brown MB. Advances in oral transmucosal drug delivery. J Control Release. 2011;153:106-116.

9. Borges AF, Silva C, Coelho JF, Simões S. Oral films: current status and future perspectives. I-Galenical development and quality attributes. J Control Release. 2015;206:1-19.

10. Dixit RP, Puthli SP. Oral strip technology: overview and future potential. J Control Release. 2009;139:94-107. doi:10.1016/j. jconrel.2009.06.014

11. Trastullo R, Abruzzo A, Saladini B, et al. Design and evaluation of buccal films as paediatric dosage form for transmucosal delivery of ondansetron. Eur J Pharm Biopharm. 2016;105:115-121. doi:10.10 16/j.ejpb.2016.05.026

12. Krampe R, Visser JC, Frijlink HW, Breitkreutz J, Woerdenbag HJ, Preis M. Oromucosal film preparations: points to consider for patient centricity and manufacturing processes. Expert Opin Drug Deliv. 2016;13:493-506. doi:10.1517/17425247.2016.1118048

13. Salamat-Miller N, Chittchang M, Johnston TP. The use of mucoadhesive polymers in buccal drug delivery. Adv Drug Deliv Rev. 2005;57:1666-1691. doi:10.1016/j.addr.2005.07.003

14. Munasur AP, Pillay V, Chetty DJ, Govender T. Statistical optimisation of the mucoadhesivity and characterisation of multipolymeric propranolol matrices for buccal therapy. Int J Pharm. 2006;323:4351. doi:10.1016/j.ijpharm.2006.05.051

15. Bansil R, Turner BS. Mucin structure, aggregation, physiological functions and biomedical applications. Curr Opin Colloid Interface Sci. 2006;11:164-170. doi:10.1016/j.cocis.2005.11.001

16. Thirawong N, Nunthanid J, Puttipipatkhachorn S, Sriamornsak P. Mucoadhesive properties of various pectins on gastrointestinal mucosa: an in vitro evaluation using texture analyzer. Eur J Pharm Biopharm. 2007;67:132-140.

17. Zargar V, Asghari M, Dashti A. A review on chitin and chitosan polymers: structure, chemistry, solubility, derivatives, and applications. ChemBioEng Rev. 2015;2:204-226.

18. Svensson O, Arnebrant T. Mucin layers and multilayersPhysicochemical properties and applications. Curr Opin Colloid Interface Sci. 2010;15:395-405. doi:10.1016/j.cocis.2010.05.015

19. Builders PF, Kunle OO, Okpaku LC, Builders MI, Attama AA, Adikwu MU. Preparation and evaluation of mucinated sodium alginate microparticles for oral delivery of insulin. Eur $J$ Pharm Biopharm. 2008;70:777-783. doi:10.1016/j.ejpb.2008.06.021

20. Cao N, Yang X, Fu Y. Effects of various plasticizers on mechanical and water vapor barrier properties of gelatin films. Food Hydrocoll. 2009;23(3):729-735. doi:10.1016/j.foodhyd.2008.07.017

21. Madhavi BR, Murthy VSN, Rani AP. Buccal film drug delivery system-an innovative and emerging technology. $J$ Mol Pharm Org Process Res. 2013;1(3):2-6. doi:10.4172/2329-9053.1000107

22. Patel MM, Smart JD, Nevell TG, Ewen RJ, Eaton PJ, Tsibouklis J. Mucin/poly (acrylic acid) interactions: a spectroscopic investigation of mucoadhesion. Biomacromolecules. 2003;4(5):1184-1190.

23. Semalty M, Semalty A, Kumar G. Formulation and characterization of mucoadhesive buccal films of glipizide. PharmSci. 2008;73:43-48.

24. Mohamad SA, Sarhan HA, Abdelkader H, Mansour HF. Vitamin B12-loaded buccoadhesive films as a non invasive supplement in vitamin B12 deficiency: in vitro evaluation and in vivo comparative study with intramuscular injection. J Pharm Sci. 2017;106:18491858. doi:10.1016/j.xphs.2017.03.040
25. Avachat AM, Gujar KN, Wagh KV. Development and evaluation of tamarind seed xyloglucan-based mucoadhesive buccal films of rizatriptan benzoate. Carbohydr Polym. 2013;91(2):537-542. doi:10.10 16/j.carbpol.2012.08.062

26. Zeng N, Seguin J, Destruel P-L, et al. Cyanine derivative as a suitable marker for thermosensitive in situ gelling delivery systems: in vitro and in vivo validation of a sustained buccal drug delivery. Int $J$ Pharm. 2017;534(12):128-135. doi:10.1016/j.ijpharm.2017.09.073

27. Ahn J-S, Choi H-K, Chun M-K, et al. Release of triamcinolone acetonide from mucoadhesive polymer composed of chitosan and poly (acrylic acid) in vitro. Biomaterials. 2002;23(6):1411-1416. doi:10.1016/S0142-9612(01)00261-7

28. Takka S, Rajbhandari S, Sakr A. Effect of anionic polymers on the release of propranolol hydrochloride from matrix tablets. Eur J Pharm Biopharm. 2001;52(1):75-82. doi:10.1016/S0939-6411(01)00147-3

29. Shah VP, Tsong Y, Sathe P, Liu J. In vitro dissolution profile comparison, statistics and analysis of the similarity factor, f2. Pharm Res. 1998;15:889-896. doi:10.1023/A:1011976615750

30. Gibaldi M. Biopharmaceutics and Clinical Pharmacokinetics. 4th edition ed. Philadelphia, USA: Lea and Febiger; 1991.

31. Ainurofiq A, Choiri S. Drug release model and kinetics of natural polymers-based sustained release tablet. Latin Am J Pharm. 2015;34:1328-1337.

32. Higuchi T. Mechanism of sustained-action medication. Theoretical analysis of rate of release of solid drugs dispersed in solid matrices. $J$ Pharm Sci. 1963;52(12):1145-1149. doi:10.1002/jps.2600521210

33. Chawla V, Tiwary AK, Gupta S. Characterization of polyvinylalcohol microspheres of diclofenac sodium: application of statistical design. Drug Dev Ind Pharm. 2000;26:675-680. doi:10.1081/DDC-100101283

34. Peppas NA, Colombo P. Analysis of drug release behaviour from swellable polymer carriers using the dimensionality index. $J$ Control Release. 1997;45:35-40. doi:10.1016/S0168-3659(96)01542-8

35. Taylan B, Capan Y, Güven O, Kes S, Hincal AA. Design and evaluation of sustained-release and buccal adhesive propranolol hydrochloride tablets. $J$ Control Release. 1996;38(1):11-20. doi:10.1016/0168-3659(95)00094-1

36. Food and Drug Administration. Center for Drug Evaluation and Research, Guidance for Industry, Bioanalytical Method Validation. USA; 2001.

37. Sahoo J, Murthy P, Biswal S, Sahoo S, Mahapatra A. Comparative study of propranolol hydrochloride release from matrix tablets with Kollidon $^{\circledR}$ SR or hydroxy propyl methyl cellulose. AAPS PharmSciTech. 2008;9(2):577-582. doi:10.1208/s12249-008-9092-2

38. Sionkowska A, Wisniewski M, Skopinska J, Kennedy CJ, Wess TJ. Molecular interactions in collagen and chitosan blends. Biomaterials. 2004;25(5):795-801.

39. Pal K, Banthia AK, Majumdar DK. Preparation and characterization of polyvinyl alcohol-gelatin hydrogel membranes for biomedical applications. Aaps Pharmscitech. 2007;8(1):E142E146. doi:10.1208/ pt080121

40. Mohamad SA, Abdelkader H, Elrehany M, Mansour HF. Vitamin B12 buccoadhesive tablets: auspicious non invasive substitute for intramuscular injection: formulation, in vitro and in vivo appraisal. Drug Dev Ind Pharm. 2019;45:244-251. doi:10.1080/036390 45.2018.1529787

41. Macêdo R, Gomes Do Nascimento T, Veras J. Compatibility and stability studies of propranolol hydrochloride binary mixtures and tablets for TG and DSC-photovisual. J Therm Anal Calorim. 2002;67(2):483-489. doi:10.1023/A:1013901332759

42. Satishbabu BK, Srinivasan BP. Preparation and evaluation of buccoadhesive films of atenolol. Indian J Pharm Sci. 2008;70:175-179. doi:10.4103/0250-474X.41451

43. Sudhakar Y, Kuotsu K, Bandyopadhyay AK. Buccal bioadhesive drug delivery - A promising option for orally less efficient drugs. J Control Release. 2006;114(1):15-40. doi:10.1016/j.jconrel.2006. 04.012 
44. Ganji F, Vasheghani FS, Vasheghani FE. Theoretical description of hydrogel swelling: a review. Iran Polym J. 2010;19(5):375-398.

45. Pedacchia A, Adrover A. Study of release kinetics and diffusion coefficients in swellable cellulosic thin films by means of a simple spectrophotometric technique. Chem Eng Res Des. 2014;92 (11):2550-2556. doi:10.1016/j.cherd.2014.03.017

46. Srivastava A, Yadav T, Sharma S, Nayak A, Kumari A, Mishra N. Polymers in drug delivery. JBM. 2016;4(01):69-84. doi:10.4236/ jbm.2016.41009

47. Singla AK, Chawla M, Singh A. Potential applications of carbomer in oral mucoadhesive controlled drug delivery system: a review. Drug Dev Ind Pharm. 2000;26(9):913-924. doi:10.1081/DDC-100101318

48. Goodrich BF. The Science of Rheology: Pharmaceutically Applied, Technical Note (1992).

49. Ojagh SM, Rezaei M, Razavi SH, Hosseini SMH. Development and evaluation of a novel biodegradable film made from chitosan and cinnamon essential oil with low affinity toward water. Food Chem. 2010;122(1):161-166. doi:10.1016/j.foodchem.2010.02.033

50. JM SW Y, Leu TL, Yang MC. Evaluation of chitosan/PVA blended hydrogel membranes. J Memb Sci. 2004;236:39-51. doi:10.1016/j. memsci.2004.02.005

51. Tejada G, Barrera M, Piccirilli G, et al. Development and evaluation of buccal films based on chitosan for the potential treatment of oral candidiasis. AAPS PharmSciTech. 2017;18(4):936-946. doi:10.1208/ s12249-017-0720-6

52. Bahri-Najafi R, Tavakoli N, Senemar M, Peikanpour M. Preparation and pharmaceutical evaluation of glibenclamide slow release mucoadhesive buccal film. Res Pharm Sci. 2014;9(3):213-223.

53. Mazzarino L, Borsali R, Lemos-Senna E. Mucoadhesive films containing chitosan-coated nanoparticles: A new strategy for buccal curcumin release. J Pharm Sci. 2014;103(11):3764-3771. doi:10.10 02/jps. 24142

54. Giovino C, Ayensu I, Tetteh J, Boateng JS. An integrated buccal delivery system combining chitosan films impregnated with peptide loaded PEG-b-PLA nanoparticles. Colloids Surf B Biointerfaces. 2013;112:9-15. doi:10.1016/j.colsurfb.2013.07.019

55. Bhise K, Dhumal R, Chauhan B, Paradkar A, Kadam S. Effect of oppositely charged polymer and dissolution medium on swelling, erosion, and drug release from chitosan matrices. AAPS Pharmscitech. 2007;8(2):E110E118. doi:10.1208/pt0802044
56. Khan G, Jiabi Z. Formulation and in vitro evaluation of ibuprofencarbopol $^{\circledR}$ 974P-NF controlled release matrix tablets III: influence of co-excipients on release rate of the drug. $J$ Controlled Release. 1998;54(2):185-190. doi:10.1016/S0168-3659(97)00225-3

57. Kumar A, Bali V, Kumar M, Pathak K. Comparative evaluation of porous versus nonporous mucoadhesive films as buccal delivery system of glibenclamide. AAPS PharmSciTech. 2013;14:1321-1332. doi:10.1208/s12249-013-0014-6

58. Sheehan J, Oates K, Carlstedt I. Electron microscopy of cervical, gastric and bronchial mucus glycoproteins. Biochemical j. 1986;239 (1):147-153. doi:10.1042/bj2390147

59. Deacon MP, McGurk S, Roberts CJ, et al. Atomic force microscopy of gastric mucin and chitosan mucoadhesive systems. Biochem $J$. 2000;348(3):557-563. doi:10.1042/bj3480557

60. Yildiz Pekoz A, Sedef Erdal M, Okyar A, et al. Preparation and invivo evaluation of dimenhydrinate buccal mucoadhesive films with enhanced bioavailability. Drug Dev Ind Pharm. 2016;42:916-925. doi:10.3109/03639045.2015.1091470

61. Koland M, Charyulu RN, Vijayanarayana K, Prabhu P. In vitro and in vivo evaluation of chitosan buccal films of ondansetron hydrochloride. Int J Pharm Investig. 2011;1:64-71. doi:10.4103/2230-973X.85967

62. Al-Dhubiab BE. In vitro and in vivo evaluation of nano-based films for buccal delivery of zolpidem. Braz Oral Res. 2016;30:e126.

63. Wang Y, Wang Z, Zuo Z, et al. Clinical pharmacokinetics of buffered propranolol sublingual tablet (Promptol ${ }^{\mathrm{TM}}$ )-application of a new "physiologically based" model to assess absorption and disposition. AAPS J. 2013;15:787-796. doi:10.1208/s12248-013-9479-1

64. Duchateau GSMJE, Zuidema J, Merkus FWHM. Bioavailability of propranolol after oral, sublingual, and intranasal administration. Pharm Res. 1986;3:108-111.

65. Mansur Ade P, Ramires JA, Avakian SD, de Paula RS, Pileggi F. Comparison of the effects of diazepam, nifedipine, propranolol and a combination of nifedipine and propranolol, by sublingual administration, in patients with hypertensive crisis. Arq Bras Cardiol. 1991;7: 313-317.
Drug Design, Development and Therapy

\section{Publish your work in this journal}

Drug Design, Development and Therapy is an international, peerreviewed open-access journal that spans the spectrum of drug design and development through to clinical applications. Clinical outcomes, patient safety, and programs for the development and effective, safe, and sustained use of medicines are a feature of the journal, which has also been accepted for indexing on PubMed Central. The manuscript management system is completely online and includes a very quick and fair peer-review system, which is all easy to use. Visit http://www. dovepress.com/testimonials.php to read real quotes from published authors. 